ARTIGOS

\section{DESAFIOS DOS MICROEMPREENDEDORES NA OBTENÇÃO DE FINANCIAMENTO: UM ESTUDO DE TRÊS SEGMENTOS DO MERCADO'}

\section{RESUMO}

Atualmente as microempresas são responsáveis por $98 \%$ dos estabelecimentos comerciais não agrícolas, correspondendo a $50 \%$ de todos os empregos formais do País. Dessa forma, este estudo procurou destacar o seguinte questionamento: quais os desafios encontrados por microempreendedores dos segmentos de indústria, comércio e serviço na obtenção de financiamento? O objetivo geral tratou de analisar os desafios enfrentados pelos microempreendedores na obtenção de financiamento por meio de um estudo de caso que abrange os segmentos: indústria, comércio e serviço. Com este intuito, o trabalho procurou entender quais os fatores que interferem nesta busca, além da aplicação e importância que esses recursos representam para a continuidade dos micronegócios. A metodologia foi de natureza quantitativa e qualitativa para permitir uma melhor análise dos dados coletados. Quanto à tipologia, caracterizou-se como descritiva e exploratória quanto aos fins, bibliográfica e múltiplos casos quanto aos meios. O instrumento utilizado para coletar os dados foi o questionário misto, mesclando perguntas do tipo objetivas e subjetivas. Com base nos resultados da pesquisa, constatou-se que, em todas as etapas da obtenção de financiamentos por parte dos microempreendedores, envolvem-se desafios a serem superados, desde a escolha dos agentes financiadores, adequação das operações quanto às taxas e prazos, documentação exigida pelas instituições, e, até mesmo, falta de conhecimento a respeito das linhas disponíveis.

Palavras-chave: Microempreendedores. Financiamento. Crédito.

Lúcio Eugênio Cerqueira Lopes lucioeugenio@gmail.com Bacharel em Administração pelo Centro Universitário Christus Fortaleza - CE - BR

Lise Alcântara Castelo lisealcantaracastelo@yahoo.com.br Mestre em Engenharia de Produção. Professora do Centro Universitário Christus - Fortaleza - CE -

\section{INTRODUÇÃO}

No atual cenário econômico carregado de constantes transformações e mudanças, aponta-se, como um dos destaques para o desenvolvimento real da economia de um país, o empreendedorismo, que desempenha um papel de importância no aquecimento do mercado interno.

Dessa forma, surge, então, a figura do empreendedor, desafiando princípios, impulsivo por desafios, correndo risco muitas ve- 
zes além de sua capacidade, com uma visão de futuro que outros não têm a capacidade de perceber, que lutam incansavelmente na esperança de ver seu sonho realizado: o seu próprio negócio!

O empreendedor aparece, portanto, no momento em que não está satisfeito com a dinâmica do dia a dia da atividade empresarial, por meio da observação de novas ideias e oportunidades de negócios inovadores, da necessidade de se produzir algo que rompa com as práticas habituais e gere sustento não só para si, mas para a comunidade em geral.

Porém, tal decisão de empreender implica uma série de desafios que deverão ser superados para a sustentação do negócio, fazendo que o ciclo de vida da empresa se prolongue e gere retornos concretos sobre os investimentos.

Nesse sentido, o Estado do Ceará, assim como o Brasil, são referências na criação de novos negócios inspirados por esta onda empreendedora, conforme dados do Serviço Brasileiro de Apoio às Micro e Pequenas Empresas (SEBRAE, 2013).

São novos negócios que surgem a todo instante e, políticas que contribuam para o favorecimento destes microempreendimentos têm papel primordial de apoio nos estágios iniciais de desenvolvimento e sustentabilidade, como a Criação da Lei Geral das Micro e Pequenas Empresas em 2006, a criação do Microempreendedor Individual (MEI), em 2009, e a ampliação dos limites de faturamento do Simples Nacional em 2012.

Destarte, percebe-se que, para extrair resultados duradouros, o empreendedor necessita de muito mais que apenas sorte e uma brilhante ideia, deverá reunir uma série de requisitos, sejam estes habilidades técnicas e/ou pessoais, ou como lidar com variáveis externas a sua atuação.

Entre as várias possibilidades de fracasso que os novos negócios estão sujeitos a enfrentar, destaca-se o fator financeiro, mais precisamente o de financiamento do capital de giro, ainda como um instrumento que pesa bastante no dia a dia do empreendedor.

Diante das informações destacadas, o presente estudo almeja contribuir nessa lacuna de estudos sobre a importância que a obtenção de financiamento possui no desenvolvimento do negócio, podendo sua adequação significar o sucesso ou a insolvência das empresas, sendo tão importante quanto o capital fixo destas, pois sua liquidez está diretamente ligada a este fator.

\section{REFERENCIAL TEÓRICO}

A fundamentação teórica que norteou a construção da pesquisa foi realizada por meio de uma discussão sobre os seguintes temas: organizações, empreendedorismo, instituições financeiras e crédito.

\subsection{ORGANIZAÇÕES}

Para Maximiano (2008), a sociedade humana é feita de organizações que fornecem os meios para o atendimento de necessidades das pessoas, em que praticamente tudo depende delas.

Dessa forma, praticamente tudo depende de algum tipo de organização e, no decorrer dos anos, várias práticas e teorias foram elaboradas a fim de melhor gerenciar os recursos e tornar tais organizações mais eficientes e eficazes.

Chiavenato (2010) complementa o assunto ressaltando que todas as principais atividades atuais são realizadas por organizações, pois tudo o que fazemos e dependemos como finanças, saúde, segurança, alimentação, etc. são desempenhadas por elas.

Ainda de acordo com Chiavenato (2011, p. 2) "as organizações são heterogêneas e diversificadas, de tamanhos diferentes, de objetivos diferentes. Existem organizações lucrativas (chamadas de empresas) e organizações não lucrativas (como Exército, Igreja, serviços públicos, entidades filantrópicas, organizações não governamentais)".

Então, o grande propósito das organizações é disponibilizar serviços e produtos que tornem a sociedade melhor, e seu estudo mostra-se de considerada importância, pois a proatividade, a criatividade e a inovação nunca foram tão necessárias como atualmente, haja vista o cenário político e econômico no qual as organizações se encontram. 


\subsection{MICRO E PEQUENAS EMPRESAS}

Sobre a criação das micro e pequenas empresas, tem-se que:

Não existe critério único universalmente aceito para definir as micro e pequenas empresas. Vários indicativos podem ser utilizados para a classificação das empresas nas categorias micro e pequena, e ainda as médias e grandes, mas eles não podem ser considerados completamente apropriados e definitivos para todos os tipos de contexto. Como afirma Filion (1990), a maioria das tentativas de definição dos tipos de empresa nos mais variados países foi feita não apenas por razões fiscais. Com elas, visa-se também a estabelecer critérios de identificação de empresas elegíveis para receber diferentes tipos de benefício oferecidos pelos governos. Por exemplo, com os critérios de definição, pode-se selecionar empresas admissíveis em programas de subcontratação (terceirização, etc.) ou de fornecimento de produtos e serviços a organizações governamentais (LIMA, 2001, p. 422).

Destarte, os critérios estabelecidos para se classificar as micro e pequenas empresas, conforme observado por Filion (1990) apud Lima (2001) são os mais variados possíveis e dependem dos países nas quais elas se instalam.

No Brasil, tais empresas foram criadas por força de Lei em 1984, e, com o passar dos anos, foram cada vez mais se aperfeiçoando. Nesse modo, ao traçar seu conceito legal, expõe-se, de acordo com SEBRAE (2013, p. 5) que:

Microempresa é um conceito criado pela Lei n. 7.256/84 e, atualmente, regulado pela Lei n. 9.841, de 5.10.99, que estabelece normas também para as empresas de pequeno porte, em atendimento ao disposto nos artigos. 170 e 179 da Constituição Federal, favorecendo-as com tratamento dife- renciado e simplificado nos campos administrativo, fiscal, previdenciário, trabalhista, creditício e de desenvolvimento empresarial.

Entretanto, o impulso obtido pelos empreendedores brasileiros, conforme citado por Bernardi (2015, p.15) foi dado somente "a partir dos anos de 1990, por meio do Plano Real, quando atingiu um grau de estabilidade econômica e restaurou a credibilidade do país perante o mundo".

No entanto, muitos ainda são os fatores que dificultam a permanência destas empresas e, para o entendimento de suas representatividades no Brasil e o porquê da importância da redução do índice de mortalidade destas, a Secretaria da Micro e Pequena Empresa (SMPE, 2015) divulgou os seguintes dados: representam 99\% dos estabelecimentos privados não agrícolas; e contribuem com $50 \%$ dos empregos formais do País.

Ao descrever-se sobre a importância de referidas empresas para o País, a obra disponível pelos órgãos SEBRAE; DIEESE (2012, p. 7) destacam o seguinte:

Entre 2000 e 2011, as micro e pequenas empresas criaram 7,0 milhões de empregos com carteira assinada, elevando o total de empregos nessas empresas de 8,6 milhões de postos de trabalho em 2000 para 15,6 milhões em 2011. Em todo o período, o crescimento médio do número de empregados nas MPE's foi de 5,5\% a.a. No período 2000-2005, foram gerados 2,4 milhões de postos de trabalho nas MPE's, um crescimento médio anual de 5,1\% a.a. Entre 2005 e 2011, esse movimento se intensificou, resultando na geração de 4,6 milhões de novos postos de trabalho, um crescimento médio anual de $5,9 \%$ a.a. $\mathrm{O}$ bom desempenho das MPE's no período analisado confirmou a sua importância para a economia. Em 2011, as micro e pequenas empresas foram responsáveis por $99 \%$ dos estabelecimentos, $51,6 \%$ dos empregos privados 
não agrícolas formais no país e quase $40 \%$ da massa de salários. Entre 2000 e 2011, de cada $\mathrm{R} \$ 100,00$ pagos aos trabalhadores no setor privado não agrícola, cerca de $\mathrm{R} \$ 40,00$, em média, foram pagos por micro e pequenas empresas. Em relação aos setores de atividade, o comércio manteve-se como a atividade com maior número de MPE's, ao responder por mais da metade do total das MPE's brasileiras. No entanto, a participação relativa do comércio caiu de $54,7 \%$ em 2000 para $51,5 \%$ do total das MPE's em 2011. Em 2011, havia cerca de 3,2 milhões de MPE no comércio.

Corroborando com o assunto, Bernardi (2015, p.14) destaca que "nenhum empreendedor sabe de onde, como e quando virão às pressões e os novos desafios a enfrentar, dado o cenário de incertezas, complexidades e riscos, afinal, este é o cerne do empreendedorismo". Até mesmo porque o candidato a empreendedor:

Ao decidir o ramo e o tamanho do negócio que irá atuar, deverá seguir alguns passos, quais sejam: escolher o endereço da empresa, o nome jurídico e o nome fantasia, registrá-la, inscrevê-la no CNPJ, na Receita Federal, na Previdência Social, na Secretaria de Fazenda Estadual, no Sindicato Patronal, obter alvará de funcionamento, e solicitar a autorização de impressão de documentos fiscais (INFOMONEY, 2015).

Em seguida, após toda a burocracia necessária, o empreendedor deverá ainda perceber que a implementação correta de Políticas Públicas e a disponibilização de linhas de créditos também por parte dos demais players de mercado, como bancos, cooperativas de crédito e agências de fomento que realmente impulsionem e possam dar-lhes um horizonte de esperança está estritamente ligado ao progresso do País, uma vez que os números se mostram de uma amplitude macro.

Percebe-se, portanto, que hoje tais empresas representam, não somente em números de empregos diretos, mais também em termos de faturamento, uma importância destacável na economia do Brasil, porém devem ser cuidadosamente planejadas.

\subsection{EMPREENDEDORISMO}

Autores como Hisrich, Peters e Shepherd (2009, p. 30) definem o empreendedorismo como:

É o processo de criar algo novo com valor, dedicando o tempo e o esforço necessários, assumindo os riscos financeiros, psíquicos e sociais correspondentes e recebendo as consequentes recompensas da satisfação e da independência financeira e pessoal.

A partir daí, identificam-se quatro aspectos básicos para o empreendedorismo: processo de criação, dedicação de tempo e esforço, recompensa de ser um empreendedor e aceitação dos eventuais riscos.

Entre os elementos citados anteriormente, o risco pode ser considerado como o grande impulsionador do empreendedorismo, uma vez que, em reação a este elemento, estes empreendedores criam, modificam produtos e situações a fim de alcançar o lucro.

Ressalte-se, entretanto que a prática do empreendedorismo no Brasil esbarra em diversos aspectos desfavoráveis, como o acesso e custo do capital, elevada carga tributária, exigências fiscais e legais, baixa capacitação para gerir o negócio, além de Políticas e Programas que não estão de acordo com a realidade do empreendedor. (SIQUEIRA; GUIMARÃES, 2007)

Com isto existem limitações ao cumprimento deste papel já que os desafios citados se tornam mais tênues nas micro e pequenas empresas devido à limitação de recursos, sejam eles de qualquer natureza. Em contrapartida, tais empresas possuem uma maior flexibilidade e velocidade no atendimento das manobras estratégicas, necessárias exigidas pelo empreendedorismo, uma vez que possuem estruturas específicas, muitas vezes até imitadas por grandes corporações. 
Oliveira (2014) destaca cinco fatores que influenciam o empreendedorismo de forma mais evidente, ressaltando não estar estabelecendo hierarquia de importância: a Situação da economia; Incentivos regionais; Modelos de novos negócios; Desemprego e Nível de relacionamentos.

Sendo assim, tais fatores externos e não controláveis pressionam o processo de desenvolvimento do empreendedorismo, em que se faz necessário avaliá-los a fim de identificar sua influência, seja ela positiva ou negativa, de longa ou curta duração no desempenho das atividades.

\subsection{EMPREENDEDOR}

De acordo com Dornelas (2013), ao comentar sobre Schumpeter (1997) em sua obra, destaca que foi ele quem primeiro definiu empreendedor, ainda, como uma das mais antigas e melhores reflexões sobre o tema em comento:

O empreendedor é aquele que destrói a ordem econômica existente pela introdução de novos produtos e serviços, pela criação de novas formas de organização ou pela exploração de novos recursos e materiais. (DORNELAS, 2013, p. 9)

Referido autor complementa o estudo destacando que a palavra "empreendedor" tem origem francesa "entrepreuneur", e quer dizer aquele que assume riscos e começa algo novo, e ainda que tal termo já era usado desde a Idade Média até a Atualidade, em que o conceito sofreu releituras até identificar realmente o que se tem hoje como empreendedorismo (DORNELAS, 2013).

Segundo Chiavenato (2008), o empreendedor não é apenas o fundador de uma empresa, ele é a energia da economia, a alavanca de recursos, o impulso de novos talentos, a dinâmica de idéias. Além disso, possui faro para oportunidades e age rapidamente a fim de aproveitá-las, assumindo assim riscos, sempre preocupado com a inovação constante.

Com isso, o empreendedor torna-se uma figura essencial na sustentabilidade do País, sendo um dos acontecimentos mais importan- tes e promissores da história econômica e social da atualidade.

Para Dolabela (1999), o empreendedor é alguém que define, por si mesmo, o que irá fazer e em que contexto será feito. Assim sendo, leva em conta seus sonhos, desejos, preferências e o estilo de vida quer ter, conseguindo dedicar-se intensamente, transformando seu trabalho em prazer.

Drucker (2008) ressalta que nem todos os donos de novos negócios podem ser considerados empreendedores, uma vez que tudo o que já foi feito muitas vezes antes, apesar dos riscos assumidos, não criam uma nova satisfação ao consumidor e muito menos uma nova demanda.

Então, a inovação incessante é o sentimento que move o empreendedor, e estes são capazes de mudar ou, até mesmo, transformar valores da área em que atuam desenvolvendo habilidades específicas, diferenciando-os dos demais e mostrando que realmente existe um algo a mais em ser empreendedor.

Hisrich, Peters e Shepherd (2009) consideram como um consenso o tipo de comportamento que abrange o perfil do empreendedor; entre eles: tomar iniciativa, organizar e reorganizar mecanismos sociais e econômicos a fim de transformar recursos e situações para proveito prático e criar o risco ou fracasso. Acrescentam ainda que é o processo de criar algo novo com determinado valor, dedicando o tempo e o esforço necessários, assumindo os riscos financeiros, psíquicos e sociais correspondentes e recebendo as consequentes recompensas da satisfação e da independência financeira e pessoal. Desse modo, referida definição abrange quatro aspectos básicos referentes ao empreendedor, uma vez que envolve o processo de criação, tempo e esforço, recompensas e oportunidade de lucro.

De acordo com Bernardi (2015, p. 43):

Há um dogma de que não é possível desenvolver o empreendedorismo, deve-se nascer empreendedor. Isso não é verdadeiro, considerando características e perfis de personalidades inatas, tomando-se por base uma analise mais 
criteriosa dos vários empreendimentos existentes, independentemente de sua etapa evolutiva. Existem várias circunstâncias que dão origem a um empreendimento e ao empreendedor, que podem ou não se relacionar aos traços de personalidade. Independentemente das várias origens, sempre há necessidade de autoavaliação quanto a vocação, motivação e perfis.

Entre os motivos que fazem surgir novos empreendedores, Oliveira (2014) cita como importantes comentários a análise da existência do espírito empreendedor, pois há dados de que, no Brasil, tal atitude é tomada apenas como necessidade de sobrevivência, diminuindo, assim, as chances sucesso.

Portanto, torna-se necessário possuir alta dose de autoconhecimento, de inteligência emocional e social, causas originais de muitos problemas, por decorrência técnicas e operacionais, criando sérios obstáculos ao empreendimento e a seu desenvolvimento, por inércia e talvez, por evolução decadente.

\subsection{INSTITUIÇÕES FINANCEIRAS}

As instituições financeiras têm um papel importante e relevante para as empresas, principalmente o de permitir, buscando a melhor condição possível, a conciliação de fluxos entre poupadores e tomadores de recursos na economia a fim de financiar o crescimento econômico.

Para Galves (2004), as instituições financeiras, ou mais especificamente, os bancos, são os agentes econômicos que têm por objetivo a coleta, a intermediação e a aplicação dos recursos monetários próprios ou de outra titularidade, sendo assim, intermediários no fluxo de dinheiro. Já Assaf Neto (2014) comenta que esta intermediação financeira produz um maior dinamismo à economia, elevando a produção e ofertando maior capacidade de consumo, essencial para a economia de um país.

Nesse sentido, as Instituições Financeiras, de acordo com a Constituição Federal de 1988 podem ser descritas ainda como:
São consideradas instituições financeiras não só os bancos de qualquer espécie, mas também as distribuidoras de valores mobiliários, corretoras de câmbio, sociedades de crédito, administradoras de cartões de crédito, cooperativas de crédito, etc. A definição é penalmente importante em virtude da previsão de sigilo das operações financeiras previsto na $\mathrm{CF} / 88$. (JURISWAY, 2015)

Devido ao sigilo exigido para a realização de operações financeiras, diversos outros intermediadores de recursos também são classificados como instituições financeiras, não se limitando a bancos como é popularmente disseminado. Dessa forma, com o intuito de uma compreensão maior sobre a apreciação de instituições financeiras e corroborando as descrições destacadas anteriormente, cita-se Vieira (2009, p. 27) quando expõe seu conceito sobre o assunto em pauta da seguinte maneira:

A Instituição Financeira é uma organização na qual o principal objetivo é otimizar a alocação de capitais financeiros próprios e/ou de terceiros, obedecendo a uma correlação de risco, custo e prazo, que atenda aos objetivos de quem os contrata, incluindo pessoas físicas ou jurídicas que tenham interesses em sua operação como acionistas, clientes, colaboradores, Cooperados, fornecedores, agências reguladoras do mercado em que a organização opere. A Instituição Financeira opera administrando um equilíbrio delicado entre moedas, prazos e taxas negociados para os capitais que capta (passivos) e para os que aplicam (ativos) no mercado, respeitando os critérios e as normas estabelecidas pelas agências reguladoras/supervisoras de cada mercado onde atue.

Portanto, o mercado para o qual os microempreendedores se dirigem para a obtenção de financiamento é bastante extenso, não se resumindo apenas a bancos, mas a quaisquer intermediários que desempenhem o papel de aloca- 
ção de capitais próprios e de terceiros a fim de obter resultados aos seus stakeholders, sempre respeitando as normas do mercado que atuam.

Para Brito (2003), as instituições financeiras podem ser divididas em duas classes distintas: as instituições públicas e privadas. As instituições financeiras privadas, segundo Assaf Neto (2014), englobam Bancos Comerciais, Bancos Múltiplos e Caixas Econômicas, devendo estas ser constituídas obrigatoriamente em forma de sociedades anônimas, tendo como principal papel executar operações de crédito em sua maioria de curto prazo, atuando, assim, diretamente nas necessidades de capital de giro das empresas; e as instituições financeiras públicas, que exercem um importante papel de fomento e apoio aos microempreendedores, pois servem como uma alternativa na obtenção de financiamentos com recursos subsidiados pelo governo.

Sendo assim, devido a ineficiência por interesses direcionados da área privada, a manutenção da estabilidade econômica e garantia do balanceamento da relação poupança $\mathrm{x}$ investimentos, as instituições públicas são protagonistas no apoio aos microempreendedores.

\subsection{CRÉDITO}

Leoni (1997) descreve que o crédito às pessoas jurídicas está diretamente ligado à colocação de seus produtos no mercado e ao equilíbrio financeiro delas, dada a sensibilidade do fluxo de caixa. Em sua obra, ele comenta que o financiador deve avaliar a empresa com uma série de dados objetivos e subjetivos, a fim de obter uma visão ampla do universo formal e informal da companhia. Entre outros aspectos observados, o autor ainda aponta o nome fantasia, as eventuais alterações societárias e o grupo a que pertence, pessoas autorizadas a assinar, etc., pois tais elementos podem identificar eventuais riscos.

Nesse contexto, cita-se Galves (2004), quando descreve que o crédito pode ser classificado de diversos pontos de vista, sendo que, quanto ao prazo, este se divide em: curto, médio e longo prazo. Sendo o primeiro com concessões entre um mês a seis meses no máximo; o segundo de seis meses a cinco anos, e o último por prazos superiores a cinco anos. São direcionadas para o longo prazo para investimentos como aquisição de máquinas e equipamentos, assim como para o curto prazo financiando o capital de giro.

As Micro e Pequenas Empresas tropeçam em maiores obstáculos na obtenção de informações e na própria concessão de crédito quando comparadas às médias e grandes empresas, seja por falta de conhecimento por parte de seus gestores, inexistência de garantias, certidões, seja por quaisquer documentos exigidos pelos agentes.

Para a Secretaria da Micro e Pequena Empresa - SMPE (2015), o crédito é um imenso impulsionador do crescimento e desenvolvimento das empresas, tendo em vista que o aumento do volume de crédito ofertado melhora consideravelmente o desempenho delas, cujo assunto é tratado de forma específica em sua atuação.

Dessa forma, de acordo com as diversas linhas de crédito disponibilizadas pelas instituições financeiras, assim como outras formas de financiamento utilizadas pelos microempreendedores, destacam-se o financiamento de capital de giro, como: empréstimos parcelados a uma taxa fixa, desconto de cheques pré-datados, antecipação de crédito para as vendas de cartão, cheque especial empresarial, financiamento do $13^{\circ}$ salário e prazo para pagamento junto a fornecedores, conforme cita o portal Emprego e Renda (2015).

\subsubsection{Microcrédito}

Voltando a Lei Geral das Microempresas e Empresas de Pequeno Porte, em seu aspecto de estímulo ao crédito, ela se apresenta:

A Lei Geral facilita a obtenção de empréstimos e reduz os custos de financiamentos para as micro e pequenas empresas. As microfinanças são fortalecidas pelo microcrédito e pelo cooperativismo de crédito. As cooperativas de crédito de micro e pequenas empresas poderão repassar recursos 
do Fundo de Amparo ao Trabalhador/ FAT, que tem mais de 120 bilhões de reais de patrimônio. Por meio de programas subsidiados pelo Governo Federal, os bancos públicos passam a oferecer linhas de crédito específicas para as micro e pequenas empresas, com juros inferiores aos juros praticados pelo mercado. (SMPE, 2015)

O SEBRAE (2014), por meio de seu relatório sobre o financiamento dos pequenos negócios do Brasil, demonstra a importância que este atributo tem no dia a dia do pequeno empreendedor, pois 8 (oito) em cada 10 (dez) empresas estavam utilizando alguma forma de financiamento.

Assim sendo, a obtenção de financiamento por parte dos microempreendedores é algo determinante na continuidade do negócio, e suas fontes de obtenção não menos importante, pois refletem a que meios eles recorrem.
Portanto, as fontes para a obtenção destes recursos, assim como sua utilização e a consciência dos microempreendedores a respeitos destes pontos foram o alvo da pesquisa, visando confrontar na análise de resultados os dados colhidos.

\section{METODOLOGIA DA PESQUISA}

A pesquisa foi realizada em três empresas de cada segmento, conforme segue: indústria, comércio e serviço. Sendo chamadas no segmento da indústria de I1, I2 e I3, no segmento do comércio $\mathrm{C} 1, \mathrm{C} 2$ e $\mathrm{C} 3$, no segmento do serviço S1, S2 e S3. Destaca-se, entretanto, que as identidades das empresas pesquisadas serão preservadas, uma vez que não se obteve a autorização para sua divulgação.

Dessa forma, o estudo as destacou conforme apresenta o Quadro 1, a seguir:

\begin{tabular}{|c|c|c|}
\hline Setor & \begin{tabular}{l|} 
Nomencla- \\
tura
\end{tabular} & Características \\
\hline \multirow{3}{*}{ Indústria } & Empresa I1 & $\begin{array}{l}\text { Empresa de doces e salgados, fundada em 2007, possui oito funcionários no regime } \\
\text { CLT e tem faturamento de cerca de R } \$ 600.000,00 \text { (seiscentos mil reais) anuais. }\end{array}$ \\
\hline & Empresa I2 & $\begin{array}{l}\text { Empresa de calçados, funcionando desde } 2008 \text {, possui trinta funcionários no } \\
\text { regime CLT e tem faturamento de cerca de R } \$ 623.700,00 \text { (seiscentos e vinte e } \\
\text { três mil e setecentos reais) anuais. }\end{array}$ \\
\hline & Empresa I3 & $\begin{array}{l}\text { Empresa de cal, fundada desde } 2000 \text {, possui nove funcionários no regime CLT } \\
\text { e tem faturamento de cerca de } \mathrm{R} \$ 588.000,00 \text { (quinhentos e oitenta e oito mil } \\
\text { reais) anuais. }\end{array}$ \\
\hline \multirow{3}{*}{ Comércio } & Empresa C1 & $\begin{array}{l}\text { Empresa do ramo de produtos para segurança eletrônica, fundada em 2010, pos- } \\
\text { sui sete funcionários no regime CLT e tem faturamento de aproximadamente R\$ } \\
540.000,00 \text { (quinhentos e quarenta mil reais) anuais. }\end{array}$ \\
\hline & Empresa C2 & $\begin{array}{l}\text { Empresa do ramo de comércio de carnes, peixes e ovos, fundada em 1994, } \\
\text { possui quatro funcionários no regime CLT e tem faturamento de cerca de R\$ } \\
480.000,00 \text { (quatrocentos e oitenta mil reais) anuais. }\end{array}$ \\
\hline & Empresa C3 & $\begin{array}{l}\text { Empresa do ramo de comércio de balas e doces que iniciou em 2002, possui } \\
\text { seis funcionários no regime CLT e tem faturamento de cerca de R } \$ 457.000,00 \\
\text { (quatrocentos e cinqüenta e sete mil reais) anuais. }\end{array}$ \\
\hline \multirow{3}{*}{ Serviço } & Empresa S1 & $\begin{array}{l}\text { Empresa de salão de beleza, fundada em 2006, possui nove funcionários no regime } \\
\text { CLT e tem faturamento de cerca de } \mathrm{R} \$ 400.000,00 \text { (quatrocentos mil reais) anuais. }\end{array}$ \\
\hline & Empresa S2 & $\begin{array}{l}\text { Empresa de serviços automotivos; funciona desde 2011, possui dezesseis fun- } \\
\text { cionários no regime CLT e tem faturamento de cerca de R\$907.000,00 (nove- } \\
\text { centos e sete mil reais) anuais. }\end{array}$ \\
\hline & Empresa S3 & $\begin{array}{l}\text { Empresa de serviços de manutenção de equipamentos eletrônicos desde } 1993, \\
\text { possui quatro funcionários no regime CLT e tem faturamento de cerca de } \\
145.900,00 \text { (cento e quarenta e cinco mil e novecentos reais) anuais. }\end{array}$ \\
\hline
\end{tabular}

Quadro 1- Características das empresas pesquisadas

Fonte: dados da pesquisa (2015). 
Portanto, o ambiente deste estudo foram as nove empresas descritas anteriormente, as quais foram pesquisadas sobre as principais fontes e os tipos de financiamentos utilizados pelos microempresários e os principais fatores que se destacam na dificuldade de se obter financiamento, para após fazer uma descrição sobre os impactos que os financiamentos geram nos negócios.

Para tal estudo, foi utilizada a metodologia qualitativa, que, segundo Lakatos e Marconi (2011), analisa e interpreta aspectos profundos e fornece maiores detalhes sobre as investigações, as atitudes, os hábitos, etc. ressaltando que difere do método quantitativo, que se preocupa com amplas amostras. Em tal forma de pesquisa, as amostras são reduzidas, e os instrumentos de coleta não são estruturados.

Em relação a sua tipologia, seguindo-se Vergara (2014), a pesquisa pode ser classificada por dois critérios básicos: quanto aos fins e quanto aos meios. Desse modo, utilizaram-se os métodos exploratório e descritivo, quanto aos fins, e bibliográfico e estudo de caso quanto aos meios.

Como instrumento de coleta de dados, foi utilizado questionário do tipo objetivo (survey), tendo em vista que a escolha deste depende da pertinência do que o pesquisador deseja investigar, extraindo daí as informações relevantes para a pesquisa científica.

\section{ANÁLISE DOS RESULTADOS}

Após a realização da pesquisa de campo, aplicada às nove empresas, conforme descrições contidas no Quadro 1, descrevem-se os resultados de acordo com o proposto no estudo por meio dos objetivos: especificar os desafios na obtenção de financiamento por parte dos microempreendedores dos setores mencionados; apresentar as principais fontes e os tipos de financiamento utilizados pelos microempresários e verificar quais os principais fatores para a dificuldade de se obter financiamento.

O questionário foi composto por 12 perguntas sobre fontes de financiamento, liberação de crédito, crédito negado, dificuldade na ob- tenção do financiamento, tipo de crédito solicitado, finalidade do crédito solicitado, exigências entre as instituições privadas e públicas, volume liberado de financiamento, taxas praticadas, utilização de financiamento, controle do nível de endividamento e recursos para pagamento de dívidas.

Tal resultado, conforme descrito no Quadro 2, destaca todas as questões e respostas das empresas entrevistadas no contexto da indústria, do comércio e serviço. 


\begin{tabular}{|l|l|l|}
\hline \multicolumn{3}{|c|}{ 1. Quais as fontes de financiamento utilizadas? } \\
\hline Empresas & \multicolumn{1}{|c|}{ Fontes de financiamento } & Comentários \\
\hline I1 & Bancos Públicos & Sem comentários \\
\hline I2 & Bancos Públicos, Prazo com fornecedores, Familiares & Sem comentários \\
\hline I3 & Bancos Privados, Prazo com fornecedores & Sem comentários \\
\hline C1 & Bancos Privados, Prazo com fornecedores & Sem comentários \\
\hline C2 & Bancos Privados, Prazo com fornecedores & Sem comentários \\
\hline C3 & Prazo com fornecedores, Familiares, Bancos Privados, Bancos Públicos & Sem comentários \\
\hline S1 & Bancos Privados, Bancos Públicos, Prazo com fornecedores & Sem comentários \\
\hline S2 & Bancos Públicos, Bancos Privados & Sem comentários \\
\hline S3 & Bancos Privados, Familiares, Bancos Públicos, Prazo com fornecedores & Sem comentários \\
\hline
\end{tabular}

\begin{tabular}{|l|l|l|}
\hline \multicolumn{2}{|c|}{ 2. Você conhece os pontos analisados para a liberação de crédito pelas instituições financeiras? } \\
\hline Empresas & \multicolumn{1}{|c|}{ Conhecimento dos pontos } & \multicolumn{1}{c|}{ Pontos analisados } \\
\hline I1 & Sim & $\begin{array}{l}\text { Possui apoio de funcionário específico para a área } \\
\text { financeira. }\end{array}$ \\
\hline I2 & Sim & $\begin{array}{l}\text { Pois precisou de financiamento para projeto e foi } \\
\text { necessário informação. }\end{array}$ \\
\hline I3 & Não & Não possui conhecimento. \\
\hline C1 & Sim & Pois já precisou diversas vezes. \\
\hline C2 & Não & Não possui conhecimento. \\
\hline C3 & Sim & Devido experiência adquirida com necessidade. \\
\hline S1 & Sim & Pois antes de abrir a empresa, elaborou planos de negócios. \\
\hline S2 & Não & Não possui conhecimento. \\
\hline S3 & Sim & $\begin{array}{l}\text { Devido a estudo de mercado realizado periodicamente e } \\
\text { especialização na área de administração. }\end{array}$ \\
\hline
\end{tabular}

\begin{tabular}{|l|l|l|}
\hline \multicolumn{3}{|c|}{ 3. Alguma vez o crédito foi negado pelas instituições financeiras? Comentar os motivos relevantes. } \\
\hline Empresas & \multicolumn{1}{|c|}{ Situação do crédito } & \multicolumn{1}{c|}{ Comentários } \\
\hline I1 & Não & $\begin{array}{l}\text { Sempre trabalhou dentro da capacidade financeira, sem histó- } \\
\text { rico de atrasos e baixo endividamento. }\end{array}$ \\
\hline I2 & Sim & Devido a problemas com os cartões de crédito \\
\hline I3 & Sim & $\begin{array}{l}\text { Devido à situação financeira do momento, quando estava com } \\
\text { alta utilização de limites. }\end{array}$ \\
\hline C1 & Não & Pois sempre honrou pagamentos em dia. \\
\hline C2 & Sim & Esteve com cadastro negativado. \\
\hline C3 & Sim & $\begin{array}{l}\text { Houve alteração do quadro societário e isto gerou recusa para } \\
\text { a liberação. }\end{array}$ \\
\hline S1 & Não & Pois sempre cumpriu as exigências das instituições. \\
\hline S2 & Sim & Empresa recém-fundada. \\
\hline S3 & Sim & Devido à alta utilização dos limites. \\
\hline
\end{tabular}

\begin{tabular}{|l|l|l|}
\hline \multicolumn{3}{|c|}{ 4. Qual o nível de dificuldade na obtenção do financiamento? Comente. } \\
\hline Empresas & \multicolumn{1}{|c|}{ Nível de dificuldade } & \multicolumn{1}{c|}{ Comentários } \\
\hline I1 & Fácil & $\begin{array}{l}\text { Devido a bom histórico junto ao mercado, não há dificuldade } \\
\text { na obtenção de financiamentos. }\end{array}$ \\
\hline I2 & Moderado & $\begin{array}{l}\text { Pois entende que há momentos mais favoráveis para a obten- } \\
\text { ção de financiamentos. }\end{array}$ \\
\hline
\end{tabular}




\begin{tabular}{|l|l|l|}
\hline I3 & Difícil & $\begin{array}{l}\text { Para a obtenção de financiamento, são exigidas certas condi- } \\
\text { çoses que dificultam o acesso. }\end{array}$ \\
\hline C1 & Fácil & Sempre que procurou a instituição, houve disponibilidade. \\
\hline C2 & Difícil & Critérios para a liberação esbarram na realidade do negócio. \\
\hline C3 & Fácil & $\begin{array}{l}\text { Considera que depende do período, mas normalmente é algo } \\
\text { fácil de ser cumprido. }\end{array}$ \\
\hline S1 & Moderado & $\begin{array}{l}\text { Pois entende que, em certos momentos, há retração ou expan- } \\
\text { são da oferta de crédito. }\end{array}$ \\
\hline S2 & Difícil & Levantar as garantias solicitadas pelo banco dificulta a obtenção. \\
\hline S3 & Moderado & Entende que, de acordo com o cenário, tal condição se altera. \\
\hline
\end{tabular}

\begin{tabular}{|l|l|l|}
\hline \multicolumn{3}{|c|}{ 5. Qual o tipo de crédito solicitado? Comente qual a finalidade. } \\
\hline Empresas & \multicolumn{1}{|c|}{ Tipo de crédito } & \multicolumn{1}{c|}{ Comentários } \\
\hline I1 & Capital de giro, Leasing de máquina. & $\begin{array}{l}\text { Modernização do maquinário, compra de ma- } \\
\text { teriais para produção. }\end{array}$ \\
\hline I2 & $\begin{array}{l}\text { Cheque especial, Cartão de crédito, Leasing } \\
\text { de máquinas. }\end{array}$ & $\begin{array}{l}\text { Compra de equipamentos, Ajuste de fluxo, Re- } \\
\text { posição de estoques }\end{array}$ \\
\hline I3 & $\begin{array}{l}\text { Cartão de crédito, Cheque especial, Capital } \\
\text { de giro. }\end{array}$ & Folha de pagamentos, Reposição de estoque \\
\hline C1 & $\begin{array}{l}\text { Capital de giro, Cartão de crédito, Cheque } \\
\text { especial. }\end{array}$ & $\begin{array}{l}\text { Reposição } \\
\text { Folha de pagamentos }\end{array}$ \\
\hline C2 & $\begin{array}{l}\text { Capital de giro, Cartão de crédito, Cheque } \\
\text { especial. }\end{array}$ & $\begin{array}{l}\text { Reposição de estoque, Reforma do prédio } \\
\text { C3 }\end{array}$ \\
\hline $\begin{array}{l}\text { Capital de giro, Cartão de crédito, Cheque } \\
\text { especial, Antecipação de recebíveis. }\end{array}$ & $\begin{array}{l}\text { Pagamento de funcionários, Ajuste de fluxo de } \\
\text { caixa, Pagamento de fornecedores, Reposição } \\
\text { de estoque. }\end{array}$ \\
\hline S1 & Capital de giro, FINAME (BNDES). & $\begin{array}{l}\text { Compra de equipamentos, Compra de matéria } \\
\text { prima }\end{array}$ \\
\hline S2 & $\begin{array}{l}\text { Cheque especial, Cartão de crédito, Capital } \\
\text { de giro. }\end{array}$ & Reposição de estoque, Folha de pagamentos. \\
\hline S3 & $\begin{array}{l}\text { Capital de giro, Cartão de crédito, Anteci- } \\
\text { pação de recebíveis, Cheque especial. }\end{array}$ & $\begin{array}{l}\text { Folha de pagamentos, Melhoria do sistema de } \\
\text { gestão, Aumento da estrutura }\end{array}$ \\
\hline
\end{tabular}

\begin{tabular}{|l|l|l|}
\hline \multicolumn{3}{|c|}{ 6. Você percebe diferenças nas exigências entre as instituições privadas e públicas? Comentar. } \\
\hline Empresas & \multicolumn{1}{|c|}{ Públicas / privadas } & \multicolumn{1}{c|}{ Comentários } \\
\hline I1 & Não & Pois somente utiliza instituições públicas. \\
\hline I2 & Não & Pois somente utiliza instituções públicas. \\
\hline I3 & Não & Pois somente utiliza instituições privadas. \\
\hline C1 & Não & Pois somente utiliza instituições privadas. \\
\hline C2 & Não & Pois somente utiliza instituções privadas. \\
\hline C3 & Sim & Instituições privadas têm mais agilidade na concessão. \\
\hline S1 & Sim & Bancos públicos liberam maiores valores com melhores condições. \\
\hline S2 & Sim & Os bancos privados têm maior agilidade. \\
\hline S3 & Sim & $\begin{array}{l}\text { Percebe que, nos bancos públicos, há maior burocracia e exigên- } \\
\text { cias de documentação que bancos particulares. }\end{array}$ \\
\hline
\end{tabular}

\begin{tabular}{|l|l|l|}
\hline \multicolumn{3}{|c|}{ 7. O volume liberado atendeu à necessidade? Comente. } \\
\hline Empresas & \multicolumn{1}{|c|}{ Volume / necessidade } & \multicolumn{1}{c|}{ Comentários } \\
\hline I1 & Sim & $\begin{array}{l}\text { Créditos liberados foram exatamente os solicitados para os } \\
\text { investimentos. }\end{array}$ \\
\hline
\end{tabular}




\begin{tabular}{|l|l|l|}
\hline I2 & Sim & Quando concedido, foi o volume solicitado. \\
\hline I3 & Não & Já houve liberações menores que a expectativa. \\
\hline C1 & Sim & Valores liberados sempre dentro do solicitado. \\
\hline C2 & Não & Valores nem sempre atendem à necessidade. \\
\hline C3 & Não & $\begin{array}{l}\text { Foram solicitados limites maiores, porém valores liberados } \\
\text { foram parciais, }\end{array}$ \\
\hline S1 & Sim & Quando solicitado já existe um cálculo para suprir as necessidades. \\
\hline S2 & Não & Valores aquém do solicitado. \\
\hline S3 & Sim & Sempre atendeu às expectativas. \\
\hline
\end{tabular}

\begin{tabular}{|l|l|l|}
\hline \multicolumn{3}{|c|}{ 8. Como você julga as taxas praticadas pelas instituições e quais os impactos no negócio? Comente } \\
\hline Empresas & Taxas praticadas & \multicolumn{1}{c|}{ Comentários } \\
\hline I1 & Baixas & Pois o crédito buscado é direcionado a pequenas indústrias. \\
\hline I2 & Altas & $\begin{array}{l}\text { Algumas linhas possuem taxa alta, o que dificulta o pagamento em } \\
\text { dia dos compromissos. }\end{array}$ \\
\hline I3 & Altas & Considera as taxas altas, o que dificulta o pagamento. \\
\hline C1 & Normais & Condições negociadas dentro do esperado. \\
\hline C2 & Normais & Taxas estavam dentro do planejado. \\
\hline C3 & Altas & Considera que menores taxas incentivariam o crescimento. \\
\hline S1 & Normais & A condição da taxa é essencial para honrar o pagamento. \\
\hline S2 & Altas & Considera que reduz o retorno dos investimentos. \\
\hline S3 & Normais & $\begin{array}{l}\text { Considera que bancos públicos têm melhores taxas, porém sem } \\
\text { grandes diferenças. }\end{array}$ \\
\hline
\end{tabular}

\begin{tabular}{|l|l|l|}
\hline \multicolumn{3}{|l|}{ 9. Como você julga os prazos praticados pelas instituições e quais os impactos no negócio? Comente. } \\
\hline Empresas & \multicolumn{1}{|c|}{ Prazos praticados } & \multicolumn{1}{c|}{ Comentários } \\
\hline I1 & Adequados & Prazo de acordo com o solicitado. \\
\hline I2 & Adequados & Prazos sempre atenderam à necessidade. \\
\hline I3 & Baixos & $\begin{array}{l}\text { Considera que prazos poderiam ser maiores para melhor condição } \\
\text { de pagamento. }\end{array}$ \\
\hline C1 & Adequados & Prazos negociados dentro do esperado. \\
\hline C2 & Baixos & Maiores prazos facilitariam o pagamento. \\
\hline C3 & Baixos & Considera que facilitaria o pagamento prazos maiores. \\
\hline S1 & Longos & Obteve financiamentode longo prazo, oqueajudou em honrarocompromisso. \\
\hline S2 & Baixos & Prazos maiores facilitariam o pagamento. \\
\hline S3 & Adequados & Bancos privados têm prazos mais curtos do que os bancos públicos. \\
\hline
\end{tabular}

\begin{tabular}{|l|l|l|}
\hline \multicolumn{2}{|c|}{ 10. Houve crescimento devido à utilização de financiamentos? } \\
\hline Empresas & \multicolumn{1}{|c|}{ Houve crescimento } & \multicolumn{1}{c|}{ Comentários } \\
\hline I1 & Sim & Nada a comentar \\
\hline I2 & Sim & Nada a comentar \\
\hline I3 & Não & Nada a comentar \\
\hline C1 & Sim & Nada a comentar \\
\hline C2 & Não & Nada a comentar \\
\hline C3 & Não & Nada a comentar \\
\hline S1 & Sim & Nada a comentar \\
\hline S2 & Sim & Nada a comentar \\
\hline S3 & Sim & Nada a comentar \\
\hline
\end{tabular}




\begin{tabular}{|l|l|l|}
\hline \multicolumn{3}{|c|}{ 11. Qual o grau de dificuldade em sobreviver sem a utilização de recursos de terceiros? Comente. } \\
\hline Empresas & \multicolumn{1}{|c|}{ Grau de dificuldade } & \multicolumn{1}{c|}{ Comentários } \\
\hline I1 & Normal & $\begin{array}{l}\text { Empresa possui programação financeira e capital de giro para } \\
\text { sobrevivência. }\end{array}$ \\
\hline I2 & Alto & Pois a empresa sempre precisa de investimentos. \\
\hline I3 & Alto & Sem recursos o funcionamento da empresa fica comprometido. \\
\hline C1 & Alto & Recursos de terceiros auxiliam a sobrevivência da empresa. \\
\hline C2 & Normal & Recursos facilitam o funcionamento, porém não são determinantes. \\
\hline C3 & Alto & $\begin{array}{l}\text { Pois, apesar de não gerar crescimento, o funcionamento da empre- } \\
\text { sa e a concessão de prazos a clientes dependem desses recursos. }\end{array}$ \\
\hline S1 & Alto & $\begin{array}{l}\text { Pois são essenciais para a aquisição de máquinas e equipa- } \\
\text { mentos, assim como pagamentos do dia a dia. }\end{array}$ \\
\hline S2 & Alto & Incentivos na concessão de créditos reduziriam o risco do negócio. \\
\hline S3 & Alto & Crescimento seria bem menor com chances de perder mercado. \\
\hline
\end{tabular}

\section{Você realiza o controle do nível de endividamento da empresa em face da capacidade de} pagamento? Comente.

\begin{tabular}{|l|l|l|}
\hline Empresas & \multicolumn{1}{|c|}{ Realiza o controle } & \multicolumn{1}{c|}{ Comentários } \\
\hline I1 & Sim & Possui gestão profissional na área financeira. \\
\hline I2 & Não & Não há gestão profissional neste sentido. \\
\hline I3 & Não & O crédito é solicitado de acordo com a demanda. \\
\hline C1 & Sim & É feito o controle da condição de pagamento da empresa. \\
\hline C2 & Sim & A demanda de crédito é controlada para evitar atrasos. \\
\hline C3 & Não & $\begin{array}{l}\text { Não de forma profissionalizada, tem noção dos valores gerais, po- } \\
\text { rém sem números exatos. }\end{array}$ \\
\hline S1 & Sim & Elabora controle sobre endividamento. \\
\hline S2 & Não & Crédito solicitado de acordo com a demanda. \\
\hline S3 & Não & Crédito solicitado de acordo com a demanda. \\
\hline
\end{tabular}

Quadro 2- Instrumento de pesquisa com as devidas respostas

Fonte: dados da pesquisa (2015).

As respostas mostram que as empresas buscam várias fontes de financiamento, como instituições financeiras privadas e públicas, prazo com fornecedores, etc. Além disso, apesar de acreditarem conhecer os pontos exigidos para as concessões, a maioria já teve recusa devido a fatores indiretos como alto consumo de limites ou cadastro negativado. No que diz respeito às linhas utilizadas, os produtos menos estruturados, como cheque especial e cartão de crédito, são os mais buscados, que devido a taxas e prazos praticados dificultam o pagamento das obrigações. Com isso, a maioria declara ter tido crescimento devido a esses financiamentos e julga como difícil a possibilidade de sobreviver sem tais incentivos.

\section{CONCLUSÕES}

Atualmente, as empresas enfrentam uma realidade de forte competição e, em maior escala, os microempreendedores, uma vez que seus recursos são mais limitados diante das grandes organizações.

Em linhas gerais, as empresas estão constantemente buscando novos caminhos para se adaptar às novas exigências do mercado, principalmente no que diz respeito à obtenção de financiamento. Entre as empresas pesquisadas, percebeu-se a importância de se investir, haja vista que tais recursos auxiliam sua sobrevivência, seja na obtenção de máquinas e equipamentos, seja em pagamentos diversos e compra de insumos.

De acordo com os resultados, observou-se que os microempresários pesquisados 
recorrem a mais de uma fonte de financiamento, em sua maioria a Bancos Privados, outros meios como Bancos Públicos e Familiares são destacados, porém em segundo lugar.

Apesar de a maioria das empresas ter afirmado conhecer os pontos analisados para a liberação de crédito, seis das pesquisadas já tiveram crédito recusado, o que traz à tona a vulnerabilidade dessas aprovações.

Quanto ao nível de dificuldade enfrentado, houve equidade entre as opções, pois devido à ciência dos motivos de recusa pela maioria, acabam compreendendo eventuais negativas.

Já com relação ao tipo de crédito solicitado e suas finalidades, o capital de giro, o cheque especial e cartão de crédito lideram a preferência desses microempreendedores, tendo cada segmento sua particularidade no emprego desses recursos, desde reposição de estoques, como o exemplo mais destacado, até a compra de equipamentos e pagamento de folha.

No que se trata a diferença nas exigências entre as instituições públicas e privadas, cinco empresas não percebem tais diferenças, porém, em comentários, alguns destes acreditam haver pequenas diferenças quanto ao prazo e taxa praticados, em que o volume liberado, em sua maioria, também atendeu às expectativas.

Dessa forma, os resultados mostraram que a dificuldade em sobreviver sem a utilização de recursos de terceiro foi proporcional às empresas no ramo da indústria e do comércio. Quanto ao setor de serviços, o grau de dificuldade apresentado foi maior.

Com o relato, sete empresas consideram que houve crescimento devido a esta utilização de recursos de terceiros para o financiamento das atividades, e este mesmo número considera como alto o grau de dificuldade em sobreviver sem esta opção. Ou seja, o financiamento dos microempresários é algo de fundamental importância para o País, tendo em vista sua representatividade nos níveis de emprego e geração de riquezas.

Foram enfrentados diversos desafios para a realização do trabalho em questão, entre eles a disponibilidade dos microempreendedores em responder ao questionário, a distância geográfica de algumas empresas, além de certa resistência a abrir as informações para a pesquisa.

Sugere-se, como fonte para futuros trabalhos, que a pesquisa seja realizada com um número maior de empreendedores, e o tema seja aprofundado visando a maiores detalhes das dificuldades enfrentadas no árduo e prazeroso processo de empreender.

\section{CHALLENGES \\ OF MICROENTREPRENEURS IN CONTRACTING FINANCING: A STUDY OF THREE MARKET SEGMENTS}

\section{ABSTRACT}

Micro enterprises account for $98 \%$ of non-farm shops, corresponding to $50 \%$ of all formal jobs in the country. The issue of this paper covers the following question: what are the challenges faced by micro-entrepreneurs of industry segments, trade and service in obtaining financing? In this sense, the general objective is to analyze the challenges faced by micro-entrepreneurs in obtaining financing through a case study covering the three segments: industry, trade and service. For that matter, the study aimed to understand what factors interfere in this search, as well as the application and importance that these resources represent for the continuity of micro businesses. The methodology of this work is qualitative and quantitative so as to allow better analysis of the collected data. A descriptive, bibliographic research and multiple cases have been used. The interview was conducted through a questionnaire answered by three micro-entrepreneurs working in three different segments. Based on the results of the survey, it was found that at every stage of obtaining financing by the micro-entrepreneurs involve challenges to be overcome, as the choice of financing agents, adequacy of operations and the rates and deadlines, required documentation by the institutions, and even lack of knowledge about the lines available. 
Keywords: Micro-entrepreneurs. Financing. Credit.

1 Artigo apresentado ao XXVI ENAGRAD - Encontro Nacional dos Cursos de Graduação em Administração, no ano de 2015, em Foz do Iguaçu - Paraná. Autores: Lúcio Eugênio Cerqueira Lopes e Lise Alcântara Castelo.

\section{REFERÊNCIAS}

ASSAF NETO, Alexandre. Mercado financeiro. 12. ed. São Paulo: Atlas, 2014.

BERNARDI, Luiz Antonio. Empreendedorismo e armadilhas comportamentais: causalidades, emoções e complexidade. São Paulo: Atlas, 2015.

BRITO, Osias Santana de. Controladoria de risco: retorno sobre instituições financeiras. São Paulo: Saraiva, 2003.

CHIAVENATO, Idalberto. Teoria geral da administração. 8. ed. Rio de Janeiro: Elsevier, 2011.

. Administração nos novos tempos. 2. ed. Rio de Janeiro: Elsevier, 2010.

Empreendedorismo: dando asas ao espírito empreendedor: empreendedorismo e viabilização de novas empresas: um guia eficiente para iniciar e trocar seu próprio negócio. 3. ed. São Paulo: Saraiva, 2008.

DOLABELA, Fernando. Oficina do empreendedor: a metodologia de ensino que te ajuda a transformar conhecimento em riqueza. São Paulo: Cultura, 1999.

DORNELAS, José. Empreendedorismo: transformando ideias em negócios. 5. ed. São Paulo: LTC, 2013.

DRUCKER, Peter. Inovação e espírito empreendedor: prática e princípios. São Paulo: Cengage Learning, 2008.
EMPREGO E RENDA. Disponível em: $<$ http:// www.portaldoempregoerenda.com.br $>$. Acesso em: 20 fev. 2015.

GALVES, Carlos. Manual de economia política atual. Revista e atualizada por Galeno Lacerda. 15. ed. Rio de Janeiro: Forense Universitária, 2004.

HISRICH, Robert D.; PETERS, Michael P.; SHEPHERD, Dean A. Empreendedorismo. 7. ed. Porto Alegre: Bookman, 2009.

INFOMONEY. Disponível em: <http://www. infomoney.com.br>. Acesso em: 10 fev. 2015.

JURISWAY. O que são consideradas instituições financeiras no Brasil? Disponível em: $<$ http://www.jurisway.org.br/v2/pergunta.asp?idmodelo=5339>. Acesso em: 25 fev. 2015.

LAKATOS, Eva Maria; MARCONI, Marina de Andrade. Metodologia científica. 6. ed. São Paulo: Atlas, 2011.

LEONI, Geraldo. Cadastro, crédito e cobrança. 3. ed. São Paulo: Atlas, 1997.

LIMA, Edmilson de Oliveira. As definições de micro, pequena e média empresas brasileiras como base para a formulação de políticas públicas. In: ENCONTRO DE ESTUDOS SOBRE EMPREENDEDORISMO E GESTÃO DE PEQUENAS EMPRESAS-EGEPE, 2., 2001, Londrina/PR. Anais... Londrina/PR: Anegepe, nov. 2001, p. 421-436. Disponível em: <www. anegepe.org.br/edicoesanteriores/londrina/ GPE2001-03.pdf>. Acesso em: 20 fev. 2015.

MAXIMIANO, Antonio Cesar Amaru. Teoria geral da administração: da revolução urbana a revolução digital. 6. ed. São Paulo: Atlas, 2008.

OLIVEIRA, Djalma de Pinho Rebouças. Empreendedorismo: vocação, capacitação e atuação direcionadas para o plano de negócios. São Paulo: Atlas, 2014. 
SCHUMPETER, Joseph Alois. Teoria do desenvolvimento econômico: uma investigação sobre lucros, capital, crédito, juro e o ciclo econômico $=$ Theorie der Wirtschaftlichen Entwicklung Dunker \& Humblot. Tradução de Redvers Opie. São Paulo: Nova Cultural Ltda, 1997.

SEBRAE - Serviço Brasileiro de Apoio às Micro e Pequenas Empresas. O financiamento dos pequenos negócios no Brasil em 2014. Brasília: UGE -Sebrae/NA, 2014.

Sobrevivência das empresas no Brasil. Brasília, 2013.

SEBRAE - Serviço Brasileiro de Apoio às Micro e Pequenas Empresas; DIEESE - Departamento Intersindical de Estatística e Estudos Socioeconômicos. Anuário do trabalho na micro e pequena empresa 2012. Brasília, 2012. Disponível em: <www.sebrae.com. br/Sebrae/ Portal\%20Sebrae/.../Anuario\%20 do\%20Trabalho>. Acesso em: 20 mar. 2015.

SIQUEIRA, Moema Miranda de; GUIMARÃES, Liliane de Oliveira. Novos desafios do empreendedorismo. Revista Administração e Diálogo, São Paulo, v. 9, n. 1, p. 144-156, 2007.

SMPE - Secretaria da Micro e Pequena Empresa. Disponível em: $<$ http://www.leigeral. com.br/portal/main.jsp?LumPag eId=FF8081812658D379012665B59AB31CE5>. Acesso em: 12 fev. 2015.

VERGARA, Sylvia Constant. Projetos e relatórios de pesquisas em administração. 15 . ed. São Paulo: Atlas, 2014.

VIEIRA, Milena Rosy Silveira. Controladoria em instituições financeiras: um estudo de caso do Banco do Nordeste do Brasil S/A. 2009. 71 f. Monografia (Graduação em Ciências Contábeis) - Faculdade Lourenço Filho, Fortaleza, 2009.

\section{BIBLIOGRAFIAS}

BANCO DO NORDESTE DO BRASIL. Disponível em: <http://www.bnb.gov.br/sobre-o-bnb>. Acesso em: 28 mar. 2015.

BATEMAN, Thomas S.; SNELL, Scott A. Administração. 2. ed. Porto Alegre: AMGH, 2012 .

BRASIL. Constituição da República Federativa do Brasil. Brasília: Senado, 1988.

CÂMARA DO COMERCIO SUÍÇO-BRASILEIRA. Instituições financeiras. Disponível em: $\quad<$ http://www.swisscam.com.br/21.-instituicoes-financeiras.html>. Acesso em: 20 mar. 2015.

CASSIOLATO, J. E.; BRITTO, J.; VARGAS, $\mathrm{M}$. Formatos organizacionais para financiamento de arranjos e sistemas de MPME. In: SEBRAE. Interagir para competir: promoção de arranjos produtivos e inovativos no Brasil. Brasília: Sebrae/Finep, 2002. p. 249-285.

COLLIS, Jill; HUSSEY, Roger. Pesquisa em administração: um guia prático para alunos de graduação e pós-graduação. 2. ed. Porto Alegre: Bookman, 2005.

CONCEITO DE CRÉDITO. Disponível em: $<$ http://www.empregoerenda.com.br/abra-a-sua-empresa/linhas-de-credito/credito-bancario>. Acesso em: 26 fev. 2015.

DEGEN, Ronald Jean. O empreendedor: empreender como opção de carreira. São Paulo: Pearson Prentice Hall, 2009.

GIL, Antônio Carlos. Estudo de caso: fundamentação científica - subsídios para coleta e análise de dados - como redigir o relatório. São Paulo: Atlas, 2009.

LEITE, Francisco Tarcísio. Metodologia científica: métodos e técnicas de pesquisa, mono- 
grafias, dissertações, teses e livros. São Paulo: Idéias e Letras, 2008.

LINS, Luiz dos Santos. Empreendedorismo: uma abordagem pratica e descomplicada. São Paulo: Atlas, 2015.

OLIVEIRA, Djalma de Pinho Rebouças. Sistemas, organizações e métodos: uma abordagem gerencial. 19. ed. São Paulo: Atlas, 2010.

PORTE e Faturamento das Empresas Segundo BNDES. Disponível em: $<$ http://www.bndes. gov.br/SiteBNDES/bndes/bndes_pt/Institucional/O BNDES/AEmpresa/>. Acesso em: 24 fev. 2015.

RODRIGUES, Rui Martinho. Pesquisa acadêmica: como facilitar o processo de preparação de suas etapas. São Paulo: Atlas, 2008.

SEBRAE - Serviço Brasileiro de Apoio às Micro e Pequenas Empresas. Cartilha geral da micro e pequena empresa. Brasília, 2012.

. Critérios de classificação de empresas: MEI - ME - EPP. Disponível em: $<$ http:// www.sebrae-sc.com.br/leis/default.asp?vedtexto $=4154>$. Acesso em: 24 fev. 2015 .

SEVERINO, Antônio Joaquim. Metodologia do trabalho científico. 23. ed. São Paulo: Cortez, 2010

SILVA, Edna Lúcia da; MENEZES, Estera Muszkat. Metodologia da pesquisa e elaboração de dissertação. 3. ed. Florianópolis: UFSC, 2001.

VERGARA, Sylvia Constant. Métodos de coleta de dados no campo. 2 . ed. São Paulo: Atlas, 2009. 